\title{
As-Used Materials for Marine Industry
}

\author{
Thi Minh Hao Dong, Van Vang Le
}

\begin{abstract}
In the strategy of marine economic development, the maritime sector plays an important role, in which seaports are the nucleus of development, the focal point for receiving and transporting import and export goods and circulating to all regions of the country. Shipping now accounts for $90 \%$ of the volume of imports and exports and part of the goods to regions, the main artery in the system of transportation and distribution of goods of the economy. The maritime industry and the world are developing and developing both in terms of quality, quality and modernity. Special welds between the various types of materials always have a number of problems that need to be addressed in order to improve the quality of welding and the life of the equipment. This paper presents and classifies the materials used in the maritime industry.
\end{abstract}

Index Terms-Material; Marine Industry; Cast Iron; Steel; Ferrous Material; Polymer.

\section{INTRODUCTION}

In some industries such as shipbuilding, rig construction, oil and gas, mechanical engineering, stainless steel welding plays a very important role [1],[2]. However, in practice stainless steel welds, especially the link between stainless steels and structural steels, are commonly encountered with the following problems:

Due to differences in crystalline structure, atomic diameter, solubility and diffusion of solid and liquid metals, etc., the mechanical durability, plasticity Weld joints when applying conventional welding technologies. Therefore, the welding of stainless steel with structural steel is considered to be much harder than other welding joints.

In the welding of stainless steel with conventional structural steel, there is a lot of residual stress, thermal stress leads to appearance of defects such as deformation, cracking of the surface, cracking due to stress corrosion [3]. This is also the most worrying issue in manufacturing plants. According to research findings, there is little scientific research involved in finding the causes and remedies for these phenomena [4].

The quality and longevity of the marine equipment are quite high in relation to the quality of the welds, especially the welds between the layers. One of these forms is the weld of stainless steel with carbon steel [5]. However, the current focus in the country to provide welding technology, not to focus on welding technology to improve the quality of welding. In addition, the research and manufacture of test equipment heat treatment welding is not properly concerned [6]. Metals are materials with properties that are conducive to construction: high strength, flexibility and high fatigue resistance. As a result, metal is widely used in construction and other engineering industries [7]. In its pure form, due to its low strength and stiffness, high plasticity, and limited

Published on October 28, 2018.

Thi Minh Hao Dong, Van Vang Le are with Ho Chi Minh city University of Transport, Ho Chi Minh city, Vietnam. use of metals. They are used primarily in the form of metal and non-metal alloys, such as carbon [8]. Its iron and alloys (steel and cast iron) are called ferrous metals; The remaining metals ( $\mathrm{Be}, \mathrm{Mg}, \mathrm{Al}, \mathrm{Ti}, \mathrm{Cr}, \mathrm{Mn}, \mathrm{Ni}, \mathrm{Cu}, \mathrm{Zn}$, etc.) and their alloys are called ferrous metals. Depending on the use and conditions of use of the metal structure, the importance of the home and the building is the use of different types of steel to withstand the different temperatures of outdoor air. The rapid development of modern industry has led to the tremendous demand for materials while simultaneously having many of the same properties that materials such as metals, ceramics and polymers stand apart [9]. durable, lightweight, low cost, high corrosion resistance. Composite (or combination of materials), which has met the requirements of recent decades, has responded, applied and developed to a high level in the law of association - a universal law. Variable in nature. Composite science and technology has been used extensively in everything from aeronautics to orthopedic materials and has grown to such an extent that many people believe that the 21 st century will be the composite civilization [10].

In some industries such as oil and gas, nuclear, shipbuilding, some welding connections between conventional carbon steel and stainless steel are being used extensively to improve corrosion resistance in working conditions, production costs are reduced. In fact, in Vietnam, the creation of welding bond between the two materials encountered a number of problems: Firstly, in the process of welding stainless steel and carbon steel is very common occurrence of deformation, hot cracking, microscopic cracking in the puddle and in the heat affected area [11],[12]. The fundamental cause is the change in microstructure during welding or the influence of alloying elements. On the other hand, these factors also lead to changes in the mechanical properties of the base metal and weld metal. Second, the technological parameters of the welding process also greatly affect the quality of the weld. The welding power, voltage, welding speed, cold environment are the basic factors that determine the organization of the welding process [13]. At present, there are many methods used in welding stainless steel such as GMAW, GTAW, SAW... However, the choice of which methods to bring the highest efficiency is still very little attention, but mainly based on experience [14]. At present, in some plants, the technology of welding stainless steel with quality carbon steel is just to stop the bonding of joints and meet the criteria of the mechanical properties of the registry. regulations. Further studies on the nature of the welding process or organizational changes, properties and factors affecting the welding process have not yet been considered [15].

Although there have been many studies in the world as well as in several Asian countries, they have also achieved certain successes in improving the quality of welded joints between steel. rust with other materials. However, the 
research results are not properly considered in Vietnam. Factories have not been able to obtain specific research results for effective application. Moreover, the welding heat treatment equipment in our country has not been specifically studied, especially welding heat treatment equipment for the marine industry, one of the sectors to use the number of raw materials.

\section{ClassificAtion OF MATERIAL USED FOR MARITIME FIELD}

\section{A. Cast iron}

As previously known, cast iron is an Fe-C alloy with carbon content exceeding $2 \%(2.14 \%$, right to point $\mathrm{E}$ of the $\mathrm{Fe}-\mathrm{C}$ state diagram). Carbon is an important element in cast iron. From the $\mathrm{Fe}-\mathrm{C}$ state diagram, it is clear that the high carbon content, the melting temperature of the cast iron is considerably lower than that of the steel, so the fact that cast iron is easier to perform than steel. Do not use cast iron> $5 \% \mathrm{C}$. The other two common elements in cast iron with a large amount ( 0.5 to over $2 \%)$ are $\mathrm{Mn}$ and $\mathrm{Si}$. These are two factors that govern the formation of graphite, the mechanical properties of cast iron. In the limited cast irons of these two elements change in a relatively wide range. Phosphorus and sulfur are two elements with a low content of 0.05 to $0.5 \%$, in which sulfur is the least harmful element to cast iron. In addition, iron can contain other elements such as alloy elements ( $\mathrm{Cr}, \mathrm{Ni}, \mathrm{Mo} \mathrm{...)}$, denatured elements $(\mathrm{Mg}, \mathrm{Ce} . .$.$) .$

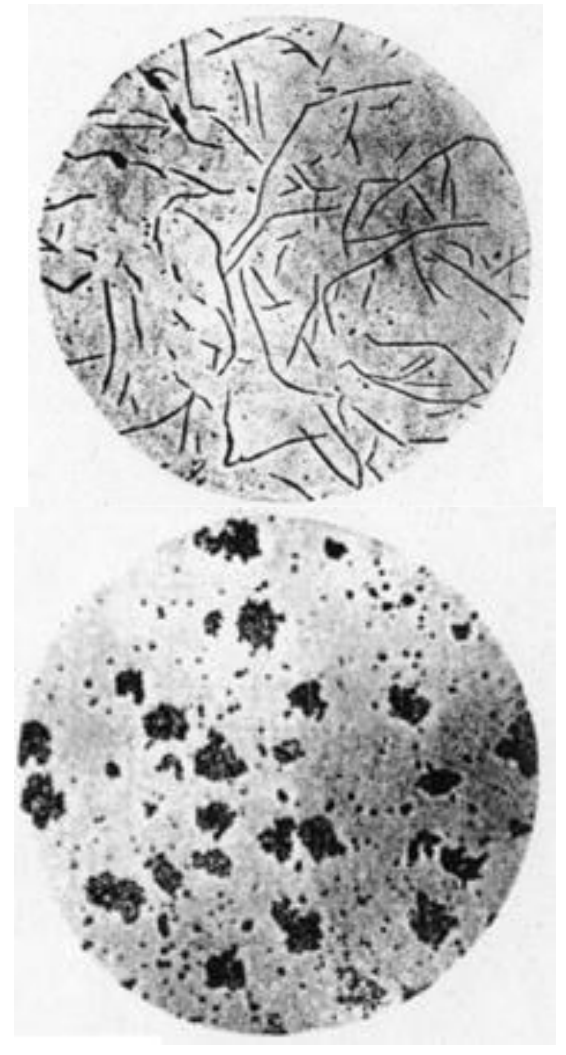

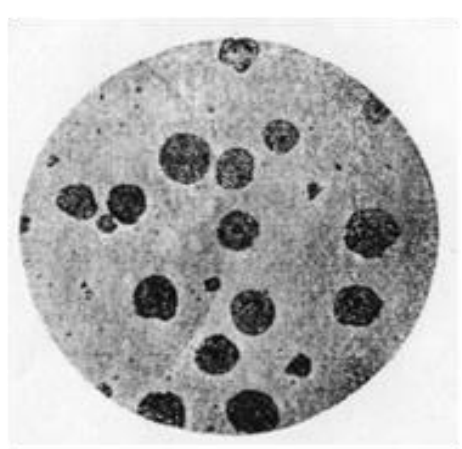

Fig. 1. Cast iron used for marine industry

According to the micro-organism, people are divided into cast iron: white cast iron, gray cast iron, cast iron, plastic cast iron. White cast iron is a cast iron in which all carbon is in the form of a bond in $\mathrm{Fe} 3 \mathrm{C}$ Xementite. Thus, the microscopic organization of white pig iron is perfectly suited to the Fe-C state diagram, which always contains a mixture of Ledeburite crystals. Gray cast iron, bridges, and plastics are cast iron in which most or all carbon is in free form - graphite with different shapes: plates, bridges, clusters. In the absence of Ledeburit, therefore, the microorganism does not conform to the $\mathrm{Fe}-\mathrm{C}$ state diagram. The microstructure of graphite cast iron depends on the distribution of carbon in the graphite and cementitious phase. They divide their organization into two parts: the nonmetal part - graphite and the metal base of ferrite and cementite. When all carbon is free, the organization's metal base consists only of ferrite. When carbon is in the link state, the base metal of the organization may be ferrite, pectite, peclitite or peclitite. It is because of the organizational nature of such casts that they have different uses and uses. To achieve a microscopic organization, each type of iron has different elemental constituents.

In general, cast iron is a material with low tensile strength, high brilliance. Xementite is a hard and brittle phase, its presence in large amounts and concentrated in cast iron makes it easy to crack under the effect of pulling load, white cast iron has low tensile strength and high brilliance.

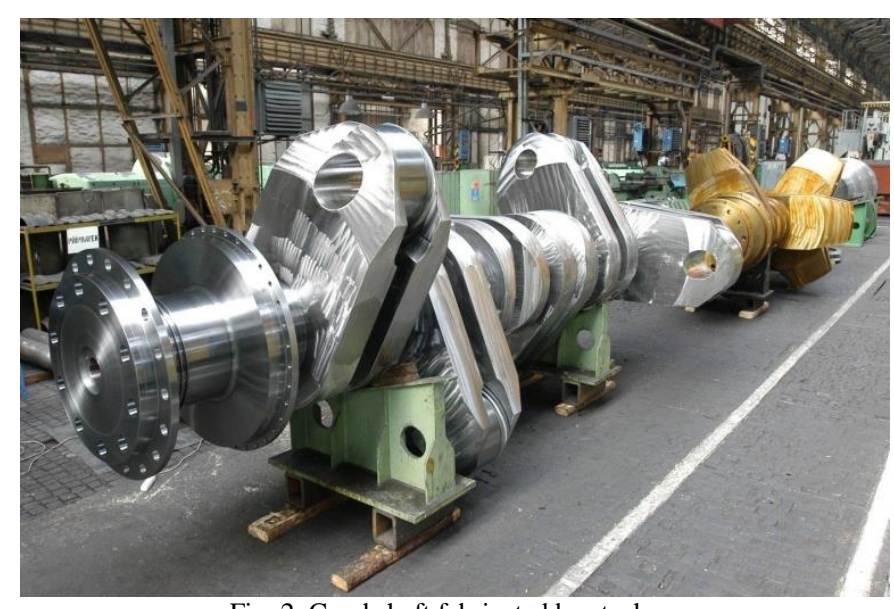

Fig. 2. Crankshaft fabricated by steel

In gray cast iron, cast iron, graphite ganglion holds graphite as holes are available in cast iron, where stress is concentrated, making cast iron unstable. The concentration of stress depends on the graphite shape, the largest in gray cast iron with the smallest graphite in graphite with round- 
shaped graphite. Thus, ductile cast iron has the highest durability coupled with the best plasticity in cast iron. In addition, the presence of graphite in cast iron has some good mechanical effects such as increased frictional wear resistance (because graphite itself is lubricated, in addition there is a "hole" of graphite that holds lubricating oil, such as when used as a sliding disk), to switch off vibration and resonance oscillations. In terms of technology, cast iron and good machining characteristics: cast irons are commonly used in the semiconductor composition, so the flow temperature is low, so the high water content is one of the important factors. molding, graphite in gray cast iron, plastic and brittle chip to break when cutting (turning, milling, planning ....). In general, cast iron is not as high synthesized as steel, but good castability, easy machining, simpler production (due to low flow temperature, molten iron and cast iron easier than steel) and cheap. Graphite castings are used extensively in mechanical manufacturing. People use cast iron to make a lot of machine parts. For example, in the car cast iron parts can account for up to $40 \%$ of the metal mass, in appliances and static machines, up to $50-80 \%$. There are many types of products used in large quantities, made of cast iron such as large water pipes. In general, cast iron is used to make static load bearing parts that are less resistant to impact such as machine supports, shells, lids, and less moving parts. There are now good casts with high mechanical strength, which can be used to replace steel in some cases, such as cast iron for crankshaft.

\section{B. Steel}

Carbon steel is a steel in the unorganized organization Ledeburite, in addition to carbon and iron there are some impurities Mn, Si, P, S. Manganese and Silicon go into the composition of steel from the following sources: Into the iron ore, so go into the composition of the cast iron and then into the steel. When steel is used, ferosilicon and ferroanganate are used to remove oxygen, so some of these elements also enter the steel. Mn and Si are two beneficial impurities, which enhance the mechanical properties of steel so that it does not matter to remove them during the process. Under normal conditions of metallurgy, they are in steel with the following amount: $\mathrm{Mn}<0.8 \%$; $\mathrm{Si}<0.50 \%$.

Phosphorus and sulfur also go into the composition of pig iron due to their existence in iron ore and fuel. For steel, both elements are harmful impurities, so during the process must remove them. $\mathrm{P}$ and $\mathrm{S}$ depletion are costly, so just reduce their constituents in steel so that the harmful effect is negligible. Generally speaking, most of the steel, the amount of each element is less than $0.05 \%$. So any carbon steel contains the following elements in the following limits: $\mathrm{C}<2 \%, \mathrm{Mn}<0.8 \%, \mathrm{Si}<0.5 \%, \mathrm{P}, \mathrm{S}<0.05 \%$.

Carbon steel is widely used in engineering and even in machine building because of two basic advantages:

Cheap, not expensive alloy elements, easy to work

There is a certain mechanical and good technology: easy to mold, rolling, forging, spinning, and stamping than for alloy steel.

However, carbon steel also has many disadvantages, including the low permeability, so that the heat treatment efficiency is not high, the temperature resistance is high, while the alloy steel outside the following High thermal properties also have some special properties such as corrosion resistance, high temperature resistance, magnetic properties and special electricity. Alloy steels have properties that are superior to carbon steels, in other words steel alloying is in the following aspects: In general, alloy steel generally has a higher durability (limited durability, flow limitation) than carbon steel, which is especially noticeable after tempering me and ram. This advantage is usually expressed in all steel alloys, the better the strength of this alloy is clear. Along with the increase in the level of alloying, the technology of steel will deteriorate. For high temperature resistance, it is found that carbon steel is relatively stable after steeling, but cannot be kept working at temperatures higher than $200^{\circ} \mathrm{C}$ because the magnesite is broken down and the aggregate is agglomerated. Alloy elements interfere with the diffusion of carbon so that the magnesium is dissociated and the carbides are agglomerated at higher temperatures, so that the alloy steel retains high mechanical strength of the mine state at temperatures above $200{ }^{\circ} \mathrm{C}$. To achieve this, steel needs to be alloyed by a relatively high number of elements.

On special physical and chemical properties, it is found that carbon steel is rusted in air, corroded in acidic, basic and saline environments, with no special physical characteristics such as magnetic expansion special heat. This requires the use of a variety of alloy steel with a strong chemical composition. It can be seen that alloy elements work very well. Alloy steels are an inexpensive metal material for heavy machinery, tools, thermoelectricity, chemical industry. It is usually made of the most important detail in heavy working condition. Each alloy element used more or less (not even used) in a particular steel group depends on its effect on the properties of the steel. It is common to see that each steel uses only one alloy element at a certain level. For example, for structural steels that require higher durability, they often use elements that enhance the permeability of chromium, manganese, nickel, and silicon, with a content of 1 to 2 percent. High speed machining tools have to use high strengths such as tungsten, cobalt, molybdenum with high content of 5-20\%. Steel with special chemical and physical properties also has special characteristics such as stainless steel containing no less than $12.5 \% \mathrm{Cr}$, abrasion resistant steel with $13 \% \mathrm{Mn}$, steel technical steel with $2-4 \% \mathrm{Si}$ etc. Commonly used elements are chromium, manganese, nickel, silicon, tungsten, molybdenum, vanadium, cobalt, titanium, and boron, in which manganese and silicon are the two most abundant elements.

Structural steel is mainly used for making machine parts (axles, gears, power transmission rods, springs, bearings etc.). Compared to conventional steels, they are used in smaller volumes, but are of a higher quality and have more variety and are often subjected to heat treatment to maximize their performance. As used in machine parts, structural steel has to meet the following two basic requirements: good machinability in the machining state (pressure processing and machining) and good synthesis Workability (mainly high impact strength at the core and high surface hardness to prevent abrasion). About the carbon content: To ensure that structural steel is usually low and medium carbon steel, usually within the range of 0.1 $0.6 \%$ highest not more than $0.65 \%$. Regarding alloying elements: Alloy elements for structural steel mainly enhance the permeability and improve the mechanical properties (ferrous bond strength), but if too much will undermine the technology and raise the price. Thus the alloy elements in structural steel used less often only 1-3\%, 
individual also only 6-7\%.

\section{Aliminum}

Unlike iron with a history of thousands of years, aluminum has a history of over a century, but has a tremendous amount of money because of its large reserves (nearly twice as much iron), light (nearly triple durable metal (highly durable aluminum alloy that has the same strengths as steel structural steel) and high corrosion resistance (higher iron content). Unlike iron, aluminum is a metal with no transformational transformation, it has only one type of crystal lattice structure, centered on the network parameter $\mathrm{a}=4.04$ atomic diameter of 2.86. Small mass $(\gamma$ $=2.7 \mathrm{~g} / \mathrm{cm}^{3}$ ) should be used extensively in aircraft manufacture. High corrosion resistance: Pure aluminum with high purity is highly corrosive and chemically very high, due to its strong affinity for oxygen, so its surface always has a thin and dense oxide layer of $\mathrm{Al} 2 \mathrm{O} 3$. tight, highly protective. The lower the cleanliness of aluminum, the less corrosion resistance it has. High conductivity and electrical conductivity: Aluminum conductivity is high, equal to $60 \%$ of copper, plus a lightweight, with the same weight, aluminum conductors are better than copper. In electrical engineering has used quite a lot of electric wire from aluminum. The aluminum conductivity is 0.3426 inches / cm.s.0C higher than iron and steel. Low flow temperatures $(6600 \mathrm{C})$ can make the process easier, but aluminum alloys do not work at high temperatures. Hiding the heat of crystallization and melting of large aluminum, so the aluminum castings slowly cooled in the liquid state facilitates the process of refining fineness. However, its castability is not high due to high shrinkage (up to 6\%). Relatively low strength: Aluminum with high purity after rolling and incubation has $\sigma_{\mathrm{b}}=60 \mathrm{~N} / \mathrm{mm} 2 ; \sigma_{0.2}=20 \mathrm{~N} /$ $\mathrm{mm} 2$, a hardness of $25 \mathrm{HB}$ is only $1 / 4$ to $1 / 6$ of the iron, so almost no pure aluminum makes the machine parts. In machines, the use of aluminum alloys is significantly higher. High flexibility: Pure aluminum is very flexible, $\delta=$ $85 \%, \delta=40 \%$ so it is easy to deform in cold state and in hot state, low cutting machinability of aluminum.

Thanks to the higher durability, aluminum is used in the manufacture of alloys. According to technology, aluminum alloys are divided into castings, deformed and sintered. Aluminum alloys and deformed aluminum alloys are produced by melting. The basis for distinguishing the boundary between the two in a given alloy system is the aluminum-alloy state diagram. Deformed aluminum alloys are alloyed aluminum alloys that are within the limits of the solid solution, i.e. to the left of the $\mathrm{C}$ 'point. It is possible that at normal temperature the alloy has not been fully held solid solution (with the second phase added) but when heated to the appropriate temperature (e.g. higher than the CD) will be held so, very Easily deformed (rolled, forged, stamped) as desired. Alloyed aluminum alloys do not contain the same crystals, which are easily deformed not only at one-phase temperature but also at normal temperatures. Within the range of the aluminum alloy deformation is divided into two groups: thermofiltrate and thermofiltrate. Alloy components on the left side of the D point when heated or cooled have no phase shift and cannot be chemically stable. The alloys at the right of the point $\mathrm{D}$ (from D to $\mathrm{C}$ '), at normal temperatures outside the solid solution also have a second phase, when heated, this phase is completely dissolved into solid solution when cooled The fast settling of the solid solution is too saturated and becomes unbalanced, releasing dispersed phases for increased durability. Aluminum alloy castings are aluminum alloys with alloying elements so that in their organization they contain essentially identical crystalline castings. In principle, the alloys to the right of the ' $C$ ' point in the molding are then co-finned and will be cast aluminum alloys, but in practice they are often used with fairly large components and finally the crystal. It is noted that the alloy aluminum alloy contains a higher amount of alloy elements than aluminum alloy deformation. Sintered aluminum alloys are aluminum alloys made from the original element of supercritical powder and sintered.

\section{Copper}

Copper is a red metal, so pure copper is technically known as copper. As a non-transforming metal, copper has only one type of crystal lattice structure, centered on a = $3,608 \mathrm{~A}^{0}$, atomic diameter of $2.56 \mathrm{~A}^{0}$. High specific gravity $=$ $8.94 \mathrm{~g} / \mathrm{cm}^{3}$ is three times larger than aluminum. High conductivity and conductivity. In this respect copper is second only to silver so it has very high application in electrical transmission and heat transfer. Good anticorrosion. Copper has high chemical stability in normal water, seawater, atmospheres and in chemical environments: organic acids, alkalis ...The temperature is relatively high $\left(1083^{\circ} \mathrm{C}\right)$, intermediate between iron and aluminum. Copper is strong, so the castings may be porous. Durability is not high but increases when cold deformation occurs. In the cast state the strength of the copper is rather low especially the flow limit $\sigma_{\mathrm{b}}=160 \mathrm{~N} / \mathrm{mm} 2, \sigma_{0.2}=35 \mathrm{~N} /$ $\mathrm{mm} 2, \mathrm{HB}=40$. In cold deformation state, limited durability and special limited Flow rate is very high $\sigma b=450 \mathrm{~N} / \mathrm{mm}^{2}$, $\sigma 0.2=400 \mathrm{~N} / \mathrm{mm}^{2}, \mathrm{HB}=125$. Therefore, one of the copper and copper alloys is durable by deformation. The hardness is not high but the corrosion resistance is quite good. The characteristic is copper is very flexible, easy to roll, drawn into thin sheets and fibers are very handy in the technical very handy in engineering, in addition it is very easy to solder. However, copper has the disadvantage of poor machining and thinning.

Copper alloys are relatively high in mechanical properties, good in technology and less friction while maintaining the advantages of copper as their thermal conductivity, conductivity and good chemical stability. The alloy elements of copper commonly used are $\mathrm{Zn}, \mathrm{Sn}, \mathrm{Al}, \mathrm{Be}, \mathrm{Mn}$, $\mathrm{Ni}$... they significantly improve the durability but actually do not do bad (in some cases also improve) plasticity in the range of concentration Determination. It can be said that plasticity is a prominent advantage of copper alloy. In terms of technology, the copper alloys are divided: deformed alloys and cast alloys. Thermal treatment is divided into two types: durable and non-chemically stable. In practice the prevailing classification of copper alloys by chemical composition. According to the chemical composition, the copper alloys are divided into two main groups: the fly ( $\mathrm{Zn}$ alloy) and the copper alloy (Zn alloys).

The general advantage of high-temperature sliding alloys is the high pressure resistance due to their high durability (which can work under high pressure conditions). Usually used in gray and gray hair.

Gray cast iron: It is usually used in high quality gray cast irons with a metal base that is fine peclitite and a large amount of graphite. The organization is of a soft, soft-core 
type, where the graphite has a near zero durability, leaving the surface exposed to "pits" that contain very good lubricants. The cheap gray cast slides have good compression but low rotational speed because of the friction coefficient of the cast iron pair (though graphite produces a lubricant effect for the slider, but not the coefficient friction of cast iron with low steel as in carbide). It is also possible to use cast iron, cast iron with P-background and austenitic gray cast iron for sliding.

Tin tongue: As stated, the slippery tin is a soft material that is solid and solid. The advantage of tin can is that it undergoes great pressure and has a higher ring speed than the gray cast iron, which often makes important slides. Can be used with the numbers BSn10V1 and BSn8Pb12. In practice it is often used with complex tins to make the lining required to resist abrasion and less friction. For the silver lining of the neck and the neck of the crankshaft, the $\mathrm{BSn} 5 \mathrm{Zn} 5 \mathrm{~Pb} 5$ (in casting state) and $\mathrm{BSn} 4 \mathrm{Zn} 4 \mathrm{~Pb} 2.5$ (in the deformed state) are used. Solid particles, in the form of individual particles, reduce friction.
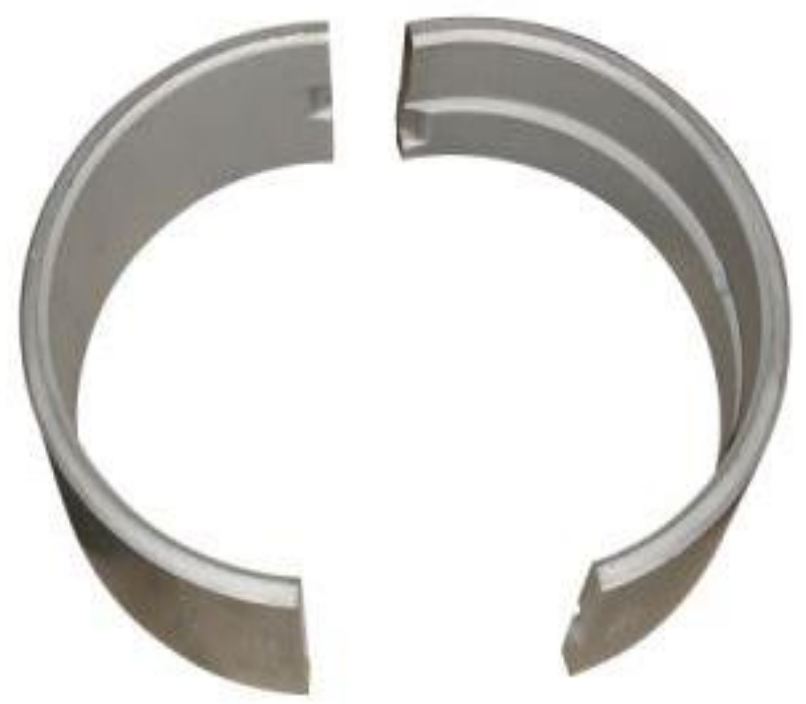

Fig. 3. Bearing of crankshaft based on BSn $5 \mathrm{Zn} 5 \mathrm{~Pb} 5$

Sticky: The lead character is characterized by low friction and high thermal conductivity, in addition to good load resistance and damping and fatigue resistance. Therefore, the lead is used as the important slider, high load and high speed as the slip of the aircraft engine, diesel, tuocbin .... $\mathrm{BPb} 30$ is currently most commonly used with about $30 \%$ lead. Because $\mathrm{Pb}$ is insoluble in $\mathrm{Cu}$ in solid state and dissolved in liquid state, therefore, when casting, it has the same geometry. Therefore, in order to avoid the phenomenon of crystallization, it is necessary to crystallize molten metal with fast speed. Simultaneously classify and place small $\mathrm{Pb}$ particles evenly distributed on the copper substrate. When working the $\mathrm{Pb}$ particles are worn out quickly to form an oil reservoir, while the $\mathrm{Cu}$ supports the shaft. The BPb30's mechanical properties are relatively low $\left(\sigma_{\mathrm{b}}=60 \mathrm{~N} / \mathrm{mm} 2, \delta=4 \%, 25 \mathrm{HB}\right)$, and mechanical properties are often cast onto steel or tubing, Further alloying with $\mathrm{Sn}$, $\mathrm{Ni}, \mathrm{Mn}$ will form a solid solution with $\mathrm{Cu}$ to improve the strength of the alloy and can be used immediately without the steel trough. When using a lead spatula, attention must be paid to the high stiffness of the shaft to prevent wear of the shaft and the lubrication of the oil must be low acidity.

\section{E. Polymer}

Plastics are materials made on the basis of polymers. Composition of various components: simple plastics polymers without additives, complex plastics - are mixtures of polymers with various additives (fillers, stabilizers, plasticizers). ...). Fillers are put into plastic with the amount of $40 \div 70 \%$ (volume) to improve the machine, reduce costs and change other parameters [16]. Fillings are organic and inorganic substances in the form of powder (wood pulp, mica, mica, $\mathrm{SiO} 2$, talcum powder, $\mathrm{TiO} 2$, graphite), fibers (cotton, glass, asbestos, polymers), sheets from different fibers, wood). Stabilizers are different organic substances that are added in a few percent to maintain molecular structure and stability [17]. Under the influence of the surrounding environment occurs the breakdown of the macromolecules into parts, and the joining of macromolecules together by horizontal connections. The initial structural change of the macromolecules is the nature of the aging phenomenon of the plasticizer. That reduces non-reversible plasticity and longevity of the details. Stabilizers slow down aging [18]. Plasticizers are added at $10 \div 20 \%$ to reduce brittleness and improve plasticity. Substances that reduce interactions between molecules and which combine well with polymers are plasticizers [19]. Often plasticizers are esters, but sometimes also plastic ones.

Special additives are lubricants, colorants, static and flame retardants, protective substances, reinforcing agents, and other solidifying agents and other substances for altering or enhancing one's properties [20]. The curing agent is added to the thermoplastic resin at a rate of several percent to harden. In this case, horizontal bonds interact with the macromolecules, while the mantle molecules are involved in the molecular network. As a curing agent, organic peroxides and other substances, sulfur (in rubber) are used. The chemical composition of the polymer is used as a basis for the classification of plastics [21]. Depending on the polymers the plastics are divided into phenol-formaldehyde resins (phenolic resins), polypropylene, polyamide, polyurethane, stirol etc. The use of plastics as a structural material is economically feasible. Compared to metal, plastic processing is less laborious, the number of materials decreases several times and the amount of scrap is not high. Normally, plastic parts do not need perfect finishing.

Characteristics of the plastic is low density $\left(12\right.$ tons $\left.\mathrm{m}^{3}\right)$, but in the plastic foam $0.016 \div 0.8$ tons $/ \mathrm{m} 3$; high chemical resistance, good electrical conductivity, low electrical conductivity $\left[0.2-0.3 \mathrm{~W} /\left(\mathrm{m} .{ }^{\circ} \mathrm{C}\right)\right]$ and significant thermal expansion, $10 \div 30$ times higher than normal steel. Because of the advantages of plastics combined with the convenience of machining, plastics are used in machine building, although plastics have limited heat tolerance, low stiffness, and toughness compared to metals.

Unlike thermoplastic plastics, thermoplastics are used extensively and are produced in large quantities. A significant proportion of thermoplastic polymers are reprocessed into films, yarns and fiber products that are difficult or impossible to manufacture from thermosetting polymers.

Loaded polymers are like viscous substances. The deformation of thermoplastic elastomers includes elastic deformation, high deformation and viscous deformation. The correlation between the deformation components varies and depends on the polymer structure as well as the 
deformation and temperature conditions. Load-bearing characteristics of plastics are complex. The standard tensile and shear tests are only mechanical approximations. The evaluation is only valid for each specific towing condition (load setting speed, temperature, sample state). Under other test conditions the results are different. Changes in external conditions and deformation rates are not entirely reflected in the mechanical properties of the alloys, which significantly alter the mechanical properties of thermoplastics and plastics in general. Mechanical sensitivity to deformation rates, load times, temperatures, and structures are typical features of thermoplastics. The glassy thermoplastic elastomers are often dilated. Deformation distortion when broken into tens to hundreds of percent. This deformation is called highly compulsive deformation; It occurs due to the elongation of the macromolecules that have been rotated under the influence of the load. When the material began to flow, the goose neck appeared in the sample. Flex is the spread of the goose neck throughout the sample. When the deformation pattern is high, do not return to zero because in the glass state the macromolecules are pulled back and cannot be retracted and will maintain the elongation.

The larger the molecular weight of polymers, the greater the deformation before the break. Similar images were observed when pulling the crystal polymer. When the crystalline polymer flows, the crystalline structure is initially replaced by a new structure in which the crystals are shaped differently and are oriented essentially the same way. This process is called re-crystallization. Reconstruction consists of three successive stages: the destruction of the crystal by the impact of stress; extends the molecule by pulling force on the destroyed crystal; New crystals appear between parallel macules. New crystals of high deformation distortion exist, so elongation remains after de-charge. Thermoplastic polymers that are oriented along the direction of orientation do not detect plastic flow. In this case the schematic draw, elongation does not exceed ten percent.

\section{CONCLUSION}

The emergence of materials technology has opened up new prospects for the shipbuilding industry and is in particular a new opportunity for achieving the goal of developing a marine economy and environmentally friendly green industry. In maritime engineering, factories usually use traditional materials for shipbuilding such as wood, steel, aluminum alloy, composite. However, finding new materials with advantages such as stainless, no aquatic species attached to the bottom and hull so it does not cost maintenance costs, maintenance of the ship and does not pollute the environment. The hydraulic resistance and fuel economy; withstand bumps; Long life, weather resistant from sound from $-35^{\circ} \mathrm{C}$ to $800^{\circ} \mathrm{C}$, good thermal insulation and sound insulation is very necessary.

\section{REFERENCES}

[1] O. Seffer, R. Lahdo, A. Springer, and S. Kaierle, "Laser-GMA hybrid welding of api 51 X70 with $23 \mathrm{~mm}$ plate thickness using $16 \mathrm{kw}$ disk laser and two GMA welding power sources," J. Laser Appl., vol. 26, no. 4, p. 42005, 2014.

[2] T. N. Le, M. K. Pham, A. T. Hoang, T. N. M. Bui, and D. N. Nguyen, "Microstructure Change For Multi-Pass Welding Between Austenitic Stainless Steel And Carbon Steel," J. Mech. Eng. Res. Dev., vol. 41, no. 2, pp. 97-102, 2018.

[3] M. K. Pham, D. N. Nguyen, and A. T. Hoang, "Influence of Vanadium Content on the Microstructure and Mechanical Properties of High-Manganese Steel," Int. J. Mech. Mechatronics Eng., vol. 18, no. 2, pp. 141-147, 2018.

[4] M. T. Miglin, J. P. Hirth, A. R. Rosenfield, and W. A. T. Clark, "Microstructure of a quenched and tempered Cu-bearing highstrength low-alloy steel," Metall. Trans. A, vol. 17, no. 5, pp. 791$798,1986$.

[5] T. N. Le, M. K. Pham, A. T. Hoang, and D. N. Nguyen, "Microstructures and elements distribution in the transition zone of carbon steel and stainless steel welds," J. Mech. Eng. Res. Dev., vol. 41 , no. 3, pp. 27-31, 2018.

[6] V. vang Le and Anh Tuan Hoang, "Marine pollution and remedies of Vietnamese Government," Int. J. Recent Eng. Res. Dev., vol. 2, no. 4, pp. 51-55, 2017.

[7] L. G. Korshunov, I. I. Kositsina, V. V Sagaradze, and N. L. Chernenko, "Effect of the carbide phase on the tribological properties of high-manganese antiferromagnetic austenitic steels alloyed with vanadium and molybdenum," Phys. Met. Metallogr., vol. 112, no. 1, p. 90,2011

[8] X. D. Pham, A. T. Hoang, and D. N. Nguyen, "A Study on the Effect of the Change of Tempering Temperature on the Microstructure Transformation of Cu-Ni-Sn Alloy," Int. J. Mech. Mechatronics Eng., vol. 18 , no. 4, pp. 27-34, 2018.

[9] X. D. Pham, A. T. Hoang, D. N. Nguyen, and V. V Le, "Effect of Factors on the Hydrogen Composition in the Carburizing Process," Int. J. Appl. Eng. Res., vol. 12, no. 19, pp. 8238-8244, 2017.

[10] D. N. Nguyen, A. T. Hoang, M. T. Sai, M. Q. Chau, and V. V. Pham, "Effect of Sn component on properties and microstructure $\mathrm{Cu}-\mathrm{Ni}-\mathrm{Sn}$ alloys," J. Teknol., vol. 80, no. 6, pp. 43-51, 2018.

[11] A. T. Hoang, L. H. Nguyen, and D. N. Nguyen, "A Study of Mechanical Properties and Conductivity Capability of CU-9NI-3SN ALLOY,” Int. J. Appl. Eng. Res., vol. 13, no. 7, pp. 5120-5126, 2018.

[12] A. T. Hoang, D. N. Nguyen, and V. V. Pham, "Heat Treatment Furnace For Improving The Weld Mechanical Properties: Design and Fabrication,” Int. J. Mech. Eng. Technol., vol. 9, no. 6, pp. 496-506, 2018.

[13] J. R. Lawrence, Advances in laser materials processing: technology, research and applications. Woodhead Publishing, 2017

[14] R. Saluja and K. M. Moeed, "The emphasis of phase transformations and alloying constituents on hot cracking susceptibility of type 304L and 316L stainless steel welds," Int. J. Eng. Sci. Technol., vol. 4, no. 5, pp. 2206-2216, 2012.

[15] R. L. Neitzel, N. S. Seixas, and K. K. Ren, "A review of crane safety in the construction industry," Appl. Occup. Environ. Hyg., vol. 16, no. 12 , pp. $1106-1117,2001$.

[16] A. T. Hoang, "A report of the oil spill recovery and treatment technologies to reduce the marine environment pollution," Int. J. eNavigation Marit. Econ., vol. 9, pp. 35-49, 2018.

[17] S. Basak, J. Nanda, and A. Banerjee, "A new aromatic amino acid based organogel for oil spill recovery," J. Mater. Chem., vol. 22, no. 23, pp. 11658-11664, 2012.

[18] A. T. Hoang, V. V Pham, and D. N. Nguyen, "A report of oil spill recovery technologies,” Int. J. Appl. Eng. Res., vol. 13, no. 7, pp. 4915-4928, 2018.

[19] A. T. Hoang, X. L. Bui, and X. D. Pham, "A novel investigation of oil and heavy metal adsorption capacity from as-fabricated adsorbent based on agricultural by-product and porous polymer," Energy Sources, Part A Recover. Util. Environ. Eff., vol. 40, no. 8, pp. 929939, 2018.

[20] A. T. Hoang et al., "An absorption capacity investigation of new absorbent based on polyurethane foams and rice straw for oil spill cleanup,” Pet. Sci. Technol., vol. 36, no. 5, pp. 361-370, 2018.

[21] H. Anh Tuan and C. Minh Quang, "A mini review of using oleophilic skimmers for oil spill recovery,” J. Mech. Eng. Res. Dev., vol. 2, no. 2, pp. 92-96, 2018. 